\title{
The effects of induced nausea upon shock-elicited aggression
}

\author{
DELMAR S. P. BISBEE and D. D. CAHOON* \\ Auburn University, Auburn, Ala. 36830
}

Albino rats were used to investigate the effects of a nausea-inducing drug (lithium chloride) upon shock-elicited aggression. Of the five groups of Ss, one received lithium chloride only, one shock only, and the remaining three groups received different levels of the injected drug plus shock. Results indicated that small amounts of the nausea-inducing drug increased aggressive responding, while larger amounts inhibited aggression. Neither simple restraint nor the drug without shock were sufficient to elicit biting responses.

It is well established that aversive stimulation may function to elicit attack in a variety of species and under a variety of conditions (e.g., O'Kelley \& Steckle, 1939; Scott \& Fredericson, 1951; Ulrich \& Azrin, 1962; Azrin, Hake, \& Hutchinson, 1965). Also, the ease of eliciting aggression with aversive stimulation seems to be influenced positively by the deprivation state of the experimental S. Deprivation conditions investigated within this framework include food deprivation (Cahoon, Crosby, Dunn, Hill, \& McGinnis, 1971; Crosby, 1971), as well as water deprivation (Hamby \& Cahoon, 1971; DeVine, 1971). Although the effects of deprivation seem curvilinear, aggression being relatively less influenced by more extensive deprivation (Crosby, 1971; DeVine, 1971), an increase in general activity as described by Finger \& Reid (1952) is not sufficient to account for the observed behavior (Crosby, 1971). The more likely explanation is that the deprivation state at lower levels contributes an aversive stimulus which summates in some manner with the externally delivered stimulation. At upper levels of deprivation, the degree of aversivity may exceed the optimum for elicitation of aggression. A similar nonlinear effect has been found with varying levels and frequencies of electric shock (e.g., Tedeschi, Tedeschi, Mucha, Cook, Mattis, \& Fellows, 1959; Ulrich \& Azrin, 1962; Azrin, Ulrich, Hutchinson, \& Norman, 1964).

The purpose of the present investigation was to assess the effects upon aggression of an internal stimulus generally accepted as aversive, nausea, and to determine if the relationship between degree of nausea and aggression is similar to that found with deprivation.

\section{METHOD \\ Subjects}

The Ss were 19 male Sprague-Dawley rats, 133-144 days of age at the initiation of the experiment. Although the animals had served earlier as control Ss in a taste aversion experiment, they

*Reprint requests may be sent to D. D. Cahoon, Department of Psychology, A uburn University, Auburn, Ala. 36830 . were experimentally naive with respect to the present project. Except for the experimental session, Ss were allowed free access to food and water.

\section{Apparatus}

The apparatus included a constant-current shocker, standard programming and recording equipment, and two rat-restraining devices of the sort described by Azrin, Rubin, \& Hutchinson (1968). Each restraining chamber consisted of a Plexiglas tube measuring $34.5 \times 8.8 \times 4 \mathrm{~cm}$ and fastened to a base by means of brass screws. A Plexiglas rod to which the S's tail could be secured was positioned at one end of the chamber, and a sliding door with a semicircular hole at the bottom edge permitted the S's tail to extend out of the chamber but prevented backing out of the apparatus. The biting target was constructed of a $.32-\mathrm{cm}$ brass rod connected to a microswitch. The end of the rod nearer the $S$ was covered with frequently replaced adhesive tape. Biting and pulling the target $.5 \mathrm{~cm}$ toward the $S$ closed the microswitch and thereby recorded an aggressive response. Lithium chloride, a highly soluble nausea-inducing drug, was dissolved in distilled water to provide a .15 molar solution $(.636 \mathrm{~g} /$ liter $)$.

\section{Procedure}

The Ss were divided without bias into four groups of four Ss each and one group of three Ss. The latter group was provided with drug-only treatment (Group D) and was not exposed to shock at any time. The other groups were assigned to one of four drug-level conditions and were additionally exposed to electrical stimulation. These conditions were: shock coupled with no drug (Group S), shock and a drug dosage level equal to $3.2 \mathrm{mg} / \mathrm{kg}$ or $.5 \%$ body weight in solution (Group $\mathrm{S} / .5 \%$ ), shock and a drug dosage level of $9.5 \mathrm{mg} / \mathrm{kg}$ or $1.25 \%$ body weight in solution $(\mathrm{S} / 1.25 \%)$, and shock and drug dosage of $12.7 \mathrm{mg} / \mathrm{kg}$ or $2 \%$ body weight in solution $(\mathrm{S} / 2 \%)$. The $1.25 \%$ dosage level was observed in a pilot investigation to produce diarrhea consistently. Therefore, $.5 \%$ and $2 \%$ levels were selected in order to extend the drug dosage parameter in either direction from the $1.25 \%$ level. All Ss were weighed before each trial and, $20 \mathrm{~min}$ before placement in the restraining chamber, injected with the appropriate amount of lithium chloride (IP). Immediately following injection, the Ss were placed in individual isolation cages to avoid association of the nausea with food or water. Group S, the only group that did not receive the drug, was placed in isolation prior to electrical stimulation. Following this preliminary phase, the $S$ was secured in the shocking apparatus

Table 1

Total Number of Biting Responses Over Sessions for Rats Exposed to Shock Only (Group S), Shock Plus .5\% Lithium Chloride (Group S/.5\%), Shock Plus 1.25\% Lithium Chloride (Group S/1.25\%), and Shock Plus 2\% Lithium Chloride (Group S/2\%)

\begin{tabular}{crrrrr}
\hline & \multicolumn{4}{c}{ Group } & \\
\cline { 2 - 5 } Session & \multicolumn{1}{c}{$\mathrm{S}$} & $\mathrm{S} / .5 \%$ & $\mathrm{~S} / 1.25 \%$ & $\mathrm{~S} / 2 \%$ & Total \\
\hline 1 & 43 & 87 & 147 & 93 & 370 \\
2 & 115 & 169 & 119 & 107 & 510 \\
3 & 150 & 293 & 57 & 50 & 550 \\
4 & 135 & 238 & 49 & 72 & 494 \\
5 & 172 & 215 & 74 & 46 & 507 \\
Total & 615 & 1002 & 446 & 368 & 2431 \\
\hline
\end{tabular}




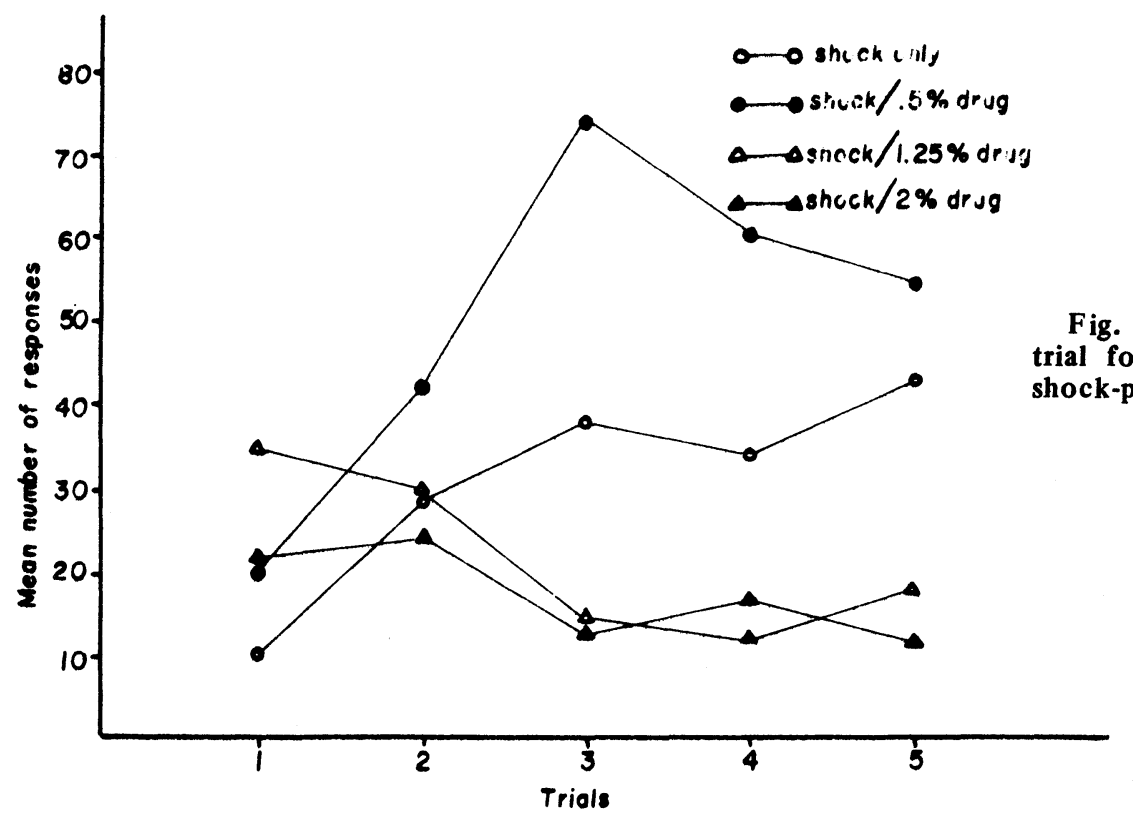

Fig. 1. Mean number of responses on each rial for the shock-only group and for the hock-plus-drug groups.

with his nose approximately $1 \mathrm{~cm}$ from the target. Following a 15-min control period during which no shocks were delivered, the rats were subjected to another $15-\mathrm{min}$ period during which they received a $.5-\mathrm{sec}$ shock of $1.5 \mathrm{~mA}$ every $3 \mathrm{sec}$ for a total of 300 shocks. Shock was administered by means of electrode clips attached to the S's tail which had been prepared with electrode jelly. The intertrial interval for the shock groups remained constant at $24 \mathrm{~h}$, although the 15 -min preshock control period was reduced to $5 \mathrm{~min}$ following the initial session due to an absence of responding during that period.

The animals in Group D (drug only) received injections of the lithium chloride solution but were not shocked. On the first trial, each of these Ss received a solution injection of $1.25 \%$ body weight, an injection of $.5 \%$ on the second trial, and an injection of $2 \%$ body weight on the third trial. Attack responses were recorded for $20 \mathrm{~min}$ on each trial, and the intertrial interval for Group D was not less than $48 \mathrm{~h}$.

All groups were run over a total of five experimental sessions.

\section{RESULTS}

The total number of biting responses over the five sessions are recorded in Table 1 for the groups exposed to shock. No attack responses were observed in the drug-only group (D) under any of the three drug-level conditions. Similarly, no biting behavior was recorded for any of the shocked Ss during the control periods in which no shocks were delivered.

An anlysis of variance performed on the results of the shock periods for the four levels of drug dosage revealed a significant difference among the groups (.05 level), and a significant Trials by Drug Levels interaction (.005 level). A Duncan's multiple range test revealed that significant differences existed between Group S/.5\% and each of the other groups (.05 level). In addition, a significant difference was discovered between Group $S$ and the $S / 2 \%$ condition. No significant differences were found between the $S / 1.25 \%$ group and either the $S$ or $\mathrm{S} / 2 \%$ group.

Since no significant differences were found across trials and a significant interaction effect was noted, it might be assumed that the drug dosage affected the learning curve for each group in such a way as to eliminate any trials effects involving summation of these groups. The mean number of responses for each group on each trial is presented in Fig. 1, and the differences in the curves for these groups are illustrated. Groups $S$ and $\mathrm{S} / .5 \%$ tend toward a greater number of responses as the number of trials is increased, and Groups $\mathrm{S} / 1.25 \%$ and $\mathrm{S} / 2 \%$ decrease over the same interval. $\mathrm{A}$ trend analysis performed on these data revealed that these tendencies were significant at the .05 level.

\section{DISCUSSION}

The finding that the nausea-inducing drug alone is not sufficient to elicit aggression is similar to those studies that indicate that deprivation does not, by itself, produce aggressive responding (Cahoon et al, 1971; Hamby \& Cahoon, 1971). The results are also similar to studies of deprivation and aggression in that aggression increases with small amounts of internal stimulation, but decreases with additional stimulation (Crosby, 1971; DeVine, 1971).

The similarity in results between the present study and the deprivation investigations may indicate that an analogous set of variables is acting in each instance. In an attempt to relate water and food deprivation to general activity, Finger (1951) and Finger \& Reid (1952) discovered the same U-shaped function in activity measures. It might be hypothesized, therefore, that small amounts of deprivation or nausea serve to increase sensitivity to external stimulation to the extent that behavior is facilitated, while larger amounts increase the organism's sensitivity to the extent that tetany results.

Much variability both within and between Ss was observed. This finding is consistent with a number of other elicited aggression studies (e.g., Azrin, Hutchinson, \& Hake, 1963, 1966), and probably reflects the influence of unknown or uncontrolled variables relating to aggression. In an attempt to rule out any effect relating to variability in size of the rats, a correlation between weight and aggressive responding was performed for each $S$ but revealed no relationship.

A question that remains is whether the results of the present experiment reflect the effects of nausea per se, or whether 
special properties of lithium chloride may be involved. Further experimentation with a different nausea-inducing drug (e.g., cyclophosphamide) would be instructive.

\section{REFERENCES}

Azrin, N. H., Hake, D. F., \& Hutchinson, R. R. Elicitation of aggression by a physical blow. Journal of the Experimental Analysis of Behavior, 1965, 8, 55-57.

Azrin, N. H., Hutchinson, R. R., \& Hake, D. F. Pain-induced fighting in the squirrel monkey. Journal of the Experimental Analysis of Behavior, $1963,6,620$.

Azrin, N. H., Hutchinson, R. R., \& Hake, D. F. Extinction-induced aggression. Journal of the Experimental Analysis of Behavior, 1966, 9, 191-204.

Azrin, N. H., Rubin, H. B., \& Hutchinson, R. R. Biting attacks by rats in response to aversive shock. Journal of the Experimental Analysis of Behavior, 1968, 11, 633-639.

Azrin, N. H., Ulrich, R. E., Hutchinson, R. R., \& Norman, D. G Effects of shock duration on shock induced fighting. Journal of the Experimental Analysis of Behavior, 1964, 7, 9-11.

Cahoon, D. D., Crosby, R. M., Dunn, S., Hill, C. G., \& McGinnis, $M$. The effect of food deprivation on shock elicited aggression in rats. Psychonomic Science, 1971, 22, 43-44.

Crosby, R. M. Elicited aggression in the albino rat as a function of food deprivation and shock stimulus patterns. Unpublished doctoral dissertation, Auburn University, 1971.

DeVine, M. D. A parametric investigation into the effects of water deprivation on shock elicited aggression. Unpublished master's thesis, Auburn University, 1971.

Finger, F. W. The effect of food deprivation and subsequent satiation upon general activity in the rat. Journal of Comparative \& Physiological Psychology, 1951, 44, 557-564.

Finger, F. W., \& Reid, L. S. The effect of water deprivation and subsequent satiation upon general activity in the rat. Journal of Comparative \& Physiological Psychology, 1952, 45, 368-372.

Hamby, W. G., \& Cahoon, D. D. The effect of water deprivation upon shock elicited aggression in the white rat. Psychonomic Science, 1971, 25, 166-167.

O'Kelly, L. E., \& Steckle, L. C. A note on long enduring emotional responses in the rat. Journal of Psychology, 1939, 8, 125-131.

Scott, J. P., \& Fredericson, E. The cause of fighting in mice and rats. Physiological Zoology, 1951, 24, 273-309.

Tedeschi, R. E., Tedeschi, D. H., Mucha, A., Cook, L., Mattis, P. A., \& Fellows, E. J. Effects of various centrally acting drugs on fighting behavior of mice. Journal of Pharmacological Experimental Therapeutics, 1959, 125, 28-34.

Ulrich, R. F., \& Azrin, N. H. Reflexive fighting in response to aversive stimulation. Journal of the Experimental Analysis of Behavior, 1962, 5, 511-520.

(Received for publication August 21, 1972.) 